\title{
Entre el mercado y el sistema punitivo. Trayectorias, proyectos de movilidad social y criminalización de mujeres en el contexto de la
}

\author{
campaña anti-trata
}

Cecilia Varela*

\section{Resumen}

En este trabajo, me propongo analizar algunos de los efectos de la implementación de la ley de trata en la Argentina. A partir de una pregunta inicial en torno a la alta criminalización de mujeres identificada en los expedientes judiciales relevados por infracción a la ley 26.364, exploro las modalidades de inserción de mujeres de sectores subalternos en el mercado sexual y sus trayectorias. En segundo lugar, exploro los procesos de reacomodamiento del mercado de departamentos privados de la CABA a partir del activo despliegue de las políticas anti-trata. Así, intento mostrar que en el contexto local los procesos judiciales abiertos por la ley 26.364 -y posteriormente por la ley 26.842- han criminalizado las trayectorias de mujeres que se han insertado en el mercado sexual inicialmente como trabajadoras y posteriormente desarrollado carreras en el sexo comercial. Discuto, así, los límites de los lenguajes legales para atender a la complejidad de las trayectorias en el mercado sexual.

Palabras claves: trata de personas-comercio sexual-criminalización secundaria- procesos judiciales-protocolo de Palermo

\section{Abstract}

In this paper, I propose to analyze some effects of the implementation of the anti-trafficking trafficking in Argentina. From an initial question about the high criminalization of women identified in judicial files, I explore the modalities in which subaltern women are included in the sexual market and their trajectories. Second, I explore the processes of market readjustment in the private departments of CABA since the deployment of anti-trafficking policies. So, I try to show that in the local context the judicial cases open by law 26.364 and later by law 26.842 - have criminalized the trajectories of women who have

\footnotetext{
* Licenciada en Ciencias Antropológicas, Orientación social, por la Facultad de Filosofía y Letras, UBA. Doctora en Filosofía y Letras con mención en Antropología, UBA. CONICET/IIEGE- UBA. Contacto: ceciliainesvarela@gmail.com
}

Varela, Cecilia "Entre el mercado y el sistema punitivo. Trayectorias, proyectos de movilidad social y criminalización de mujeres en el contexto de la campaña anti-trata", en Zona Franca. Revista del Centro de estudios Interdisciplinario sobre las Mujeres, y de la Maestría poder y sociedad desde la perspectiva de Género, N²4, 2016 pp. 7-37. ISSN, 2545-6504

Recibido: 02 de mayo de 2016; Aceptado: 31 de mayo de 2016 
been inserted into the sexual market initially as workers and later developed careers in commercial sex. I discuss the limits of the legal language to address the complexity of trajectories in the commercial sex.

Key words: human trafficking- commercial sex-secondary criminalization, judicial processes-Palermo Protocol

En los últimos años, hemos presenciado en Argentina al lanzamiento de un sinnúmero de medidas y acciones dirigidas a combatir la trata de personas con fines de explotación sexual. Los medios de comunicación publicitan, casi cotidianamente, procedimientos policiales y judiciales a través de los cuales se anuncia el desmantelamiento de redes organizadas de trata para la explotación sexual. Imputaciones penales, allanamientos, cierres de whiskerías y cabarets, clausuras de domicilios, rescate de víctimas, entre otras medidas, son los materiales con los cuales agentes de la política local (pertenecientes a un amplio espectro político) construyen imágenes de un gestión institucional eficaz contra lo que se ha dado en llamar "el flagelo de la trata" o "la esclavitud del siglo XXl"

La campaña anti-trata en la Argentina presenta un esquema binario en el que víctimas y victimarios configuran un escenario exento de toda ambigüedad moral. Por un lado, los tratantes son descriptos siempre como varones, tan violentos como peligrosos, miembros de sofisticadas redes criminales que actúan impunemente a lo largo de fronteras. Por otro lado, este discurso elabora la figura de la víctima perfecta o adecuada articulando un conjunto de estereotipos de género tradicionales, donde la inocencia sexual y la pasividad de las mujeres son centrales (Doezema, 2004; Agustín, 2009).

En contraste con las retóricas habitualmente desplegadas por la campaña, un análisis de los procesos judiciales que en la Argentina fueron 
posibles a partir de la sanción de la ley 26.364 muestra una alta criminalización de mujeres por el delito de trata con fines de explotación sexual. Esto significa que muchas mujeres son identificadas jurídicamente como responsables del "reclutamiento" de otras mujeres para el mercado sexual, tanto como responsables de la explotación de la prostitución ajena. En este trabajo intento mostrar que en el contexto local los procesos judiciales abiertos por la ley 26.364 - y posteriormente por la ley 26.842 - han criminalizado las trayectorias de mujeres que se han insertado en el mercado sexual inicialmente como trabajadoras y posteriormente desarrollado carreras en el sexo comercial ${ }^{1}$. Así, retomando la metáfora propuesta por Cohen (1985) en su libro "Visiones del control social", planteo que las leyes anti-trata han producido una ampliación de las redes de pesca y un aumento de su densidad de manera tal que hoy es posible capturar más peces pero cada vez más pequeños. Esta reflexión pretende contribuir a una discusión más amplia - sobre todo desarrollada en el ámbito de la criminología feminista- en torno a las potencialidades y los límites del derecho penal como herramienta para proteger a las mujeres (Larrauri, 1994; Pitch, 1995; Bodelon, 1998).

Para esta indagación, me baso en el análisis cuanti/cualitativo de 156 sentencias condenatorias derivadas de 101 expedientes judiciales iniciados entre abril del 2008 y diciembre del 2010 en distintas jurisdicciones de todo el

\footnotetext{
${ }^{1}$ Sigo aquí la propuesta de Agustin (2005) quien propone la etiqueta "sexo comercial" para comprender un amplio rango de intercambios de bienes comerciales y servicios que poseen un elemento erótico o sexual. Mientras algunos de estos intercambios son etiquetados como "prostitución", otros no lo son. Así, este último término puede resultar en ocasiones conceptualmente impreciso, remitiendo más bien al estigma asociado a determinados intercambios de sexo por bienes económicos (Petherson, 1996; Juliano, 2002). A su vez, su uso invisibiliza la diversidad de estos intercambios, tanto como oscurece la compresión respecto de la existencia de un mercado constituido por el juego de la oferta y demanda de servicios sexuales (Agustin, 2005; Piscitelli, 2013).
} 
país. A su vez, me apoyo en las entrevistas que realicé a mujeres procesadas y condenadas por el delito de trata de personas y mi trabajo de campo en el circuito del sexo comercial de la Ciudad de Buenos Aires durante el año 2013.

En la primera parte historizo brevemente la sanción de las dos leyes anti-trata que configuran el marco de la investigación que vengo realizando. En segundo lugar, analizo algunos rasgos de los procesos de criminalización a partir de la implementación de la ley 26.364 atendiendo a la distribución de las sentencias condenatorias relevadas, las modalidades de inserción de mujeres de sectores subalternos en el mercado sexual y sus trayectorias en el sexo comercial. Por último, exploro los procesos de reacomodamiento del mercado de departamentos privados de la CABA a partir del activo despliegue de las políticas anti-trata.

\section{Breve historia sobre la ley de trata en la Argentina}

El debate en torno a la definición del delito de trata en espacios supranacionales tiene una larga historia vinculada a los posicionamientos sobre el estatuto que debería adoptar la oferta de servicios sexuales (WijersLapChew, 1999; Doezema, 2010), al punto que la campaña anti-trata ha sido considera una reactualización de los debates sobre prostitución (GulcurIlkkaracan, 2002). Mientras las organizaciones de trabajadoras sexuales y las feministas que apoyan el reconocimiento de sus derechos laborales proponen que el uso de la fuerza o el engaño sea un elemento necesario para deslindar el delito de trata de las migraciones asociadas al mercado sexual, para el feminismo abolicionista cualquier colaboración para la inserción en el mercado sexual debe ser considerada un delito de trata de personas. 
La definición elaborada por el Protocolo de Palermo, y adoptada por Argentina originalmente en el año 2008 a través de la ley 26.364, intentó saldar, no sin ambigüedades, estas distintas posiciones. Así, de acuerdo a los estándares fijados por este instrumento internacional, la ley argentina definió como trata de personas mayores de edad:

...la captación, el transporte y/o traslado - ya sea dentro del país, desde o hacia el exterior-, la acogida o la recepción de personas mayores de 18 años de edad, con fines de explotación, cuando mediare engaño, fraude, violencia, amenaza o cualquier medio de intimidación o coerción, abuso de autoridad o de una situación de vulnerabilidad, concesión o recepción de pagos o beneficios para obtener el consentimiento de una persona que tenga autoridad sobre la víctima, aun cuando existiere asentimiento de ésta.

La ley no requería que mediara ninguna de las circunstancias mencionadas (tales como engaño, coerción y abuso de situación de vulnerabilidad) cuando se tratara de menores de edad y definía que en ambos casos (mayores y menores de edad) el consentimiento prestado resultaba irrelevante. Finalmente, estas definiciones propuestas desde los espacios supranacionales dejaban ambigüedades y lagunas, sobre todo en torno al concepto de "vulnerabilidad" y "explotación sexual" (Doezema, 2010; Piscitelli, 2008).

La ley 26.364 fue desde el momento de su sanción en el año 2008 un objeto polémico. El emergente campo de las organizaciones anti-trata locales (un amplio espectro que incluye colectivos feministas autónomos, organizaciones no gubernamentales activas en temáticas de género y organizaciones vinculadas a la Iglesia Católica) se embarcó en una fuerte campaña para la inmediata modificación del tipo penal. Las organizaciones, informadas por el abolicionismo de la prostitución, auguraban todo tipo de 
dificultades en los futuros procedimientos judiciales y proponían eliminar la distinción entre personas mayores y menores de edad en la ley.

Si bien las críticas fueron contestadas desde un punto de vista jurídico (García Mendezet al., 2008) y no se presentaron estudios o evidencias concretas que mostraran las mencionadas dificultades en los procesos judiciales, el argumento lograba circular a través de fórmulas autoevidentes (“¿Cómo podría una persona tener que probar que no consintió su propia esclavitud?") y se imponía a través de la fuerza de las imágenes estereotipadas sobre el comercio sexual. La indistinción entre personas mayores y menores de edad, tanto como la expresión cuya inclusión proponían en el texto legal ("aún con el consentimiento de la víctima") más que salvaguardar las potenciales dificultades prácticas de los procedimientos judiciales, buscaba consagrar la idea de que la prostitución constituye per se una forma de violencia contra las mujeres y una forma de esclavitud contemporánea (Varela, 2012). Así, las organizaciones anti-trata -en sintonía con los debates en espacios transnacionales y supranacionales- buscaban profundizar la perspectiva abolicionista de la legislación argentina, derribando cualquier distinción posible entre prostitución libre y forzada².

En diciembre de 2012 se conoció el fallo absolutorio a los procesados por el secuestro de Marita Verón, cuya desaparición en el año 2002 había sido

\footnotetext{
${ }^{2}$ Doezema (2005) señala que el movimiento de trabajadoras sexuales elaboró la distinción entre "forzada" y "libre" como respuesta a los intentos de algunos sectores del feminismo de incluir a la prostitución como una forma de violencia contra las mujeres durante la década del noventa. Ello permitía mantenerse leal a la estrategia feminista de visibilizar los temas de violencia contra las mujeres pero habilitando un espacio para la reivindicación de derechos por parte de las trabajadoras sexuales.
}

Revista Zona Franca- Centro de estudios interdisciplinario sobre las mujeres (CEIM)- Maestría poder y sociedad desde la perspectiva de género (MG), Rosario, Argentina. ISSN, 2545-6504 http://zonafranca.unr.edu.ar/index.php/ZonaFranca| Numero 24 (2016). 
adjudicada a una red de explotación sexual ${ }^{3}$. El tribunal local reconoció la existencia de un circuito de explotación sexual, pero decidió absolver a los imputados del secuestro por el beneficio de la duda. El caso había logrado una enorme repercusión pública y su resolución generó un fuerte clima de indignación social, movilizaciones en las calles y expresiones de repudio de todo el arco político. La sentencia que no consideraba el delito de "trata" -ya que al momento de su desaparición la ley 26.364 no se encontraba vigente- fue exhibida por las organizaciones anti-trata como la prueba cabal de que el tipo penal debía modificarse porque los jueces "no escuchaban a las víctimas". En un contexto álgido, el Congreso aprobó la modificación de los tipos penales del delito de trata de personas y explotación sexual de acuerdo a las demandas que las organizaciones anti-trata habían formulado en los años precedentes. Así, la ley 26.842 definió como por trata de personas: "...el ofrecimiento, captación, el traslado, la recepción o acogida de personas con fines de explotación, ya sea dentro del territorio nacional, como desde o hacia otros países"

Una de las formas de "explotación" definida por la ley fue la promoción, facilitación y comercialización de "la prostitución ajena o cualquier otra forma de oferta de servicios sexuales ajenos".A su vez, la nueva ley modificó y amplió también los tipos penales correspondientes al delito de "proxenetismo" (Art.127) y "promoción de la prostitución" (Art. 126) con un criterio similar.

En síntesis, si bien la amplitud de las acciones contenidas en la primera redacción de la ley ("captar", "trasladar", "acoger") ya implicaba la posibilidad

\footnotetext{
${ }^{3}$ La desaparición había ocurrido en el año 2002, pero el caso había terminado por obtener una amplísima repercusión pública a partir del año 2007, cuando el Departamento de Estado de los Estados Unidos reconoció a su madre, Susana Trimarco, por su extensa lucha en búsqueda de su hija como "Madre Coraje".
}

Revista Zona Franca- Centro de estudios interdisciplinario sobre las mujeres (CEIM)- Maestría poder y sociedad desde la perspectiva de género (MG), Rosario, Argentina. ISSN, 2545-6504 http://zonafranca.unr.edu.ar/index.php/ZonaFranca| Numero 24 (2016). 
de criminalizar a los dueños de los establecimientos, los colaboradores de los procesos migratorios y las terceras partes en el mercado sexual (recepcionistas, encargadas, personal de seguridad) independientemente de que las consideradas "víctimas" participaran voluntariamente del comercio sexual $^{4}$, la modificación del año 2012 profundizó esta orientación, eliminó la posibilidad de distinguir entre prostitución forzada y libre en los procedimientos judiciales y elevó las penas previstas. Además, la modificación de la ley en el contexto de un escándalo judicial estimuló la multiplicación de los operativos y contribuyó a consolidar la equivalencia entre prostitución y trata de personas que venían impulsando las organizaciones abolicionistas.

\section{Políticas anti-trata y criminalización de mujeres}

La Argentina no dispone de un sistema de información de estadística criminal centralizado y confiable. Sobre las debilidades de las estadísticas oficiales de la criminalidad, la recolección "artesanal" de expedientes judiciales emerge como una alternativa para construir un análisis de los procesos judiciales llevados adelante por la ley $26.364^{5}$. El corpus está integrado por 156 sentencias condenatorias por delitos de trata de personas con fines de

\footnotetext{
${ }^{4}$ En paralelo a la discusión pública sobre la reforma de la ley y de manera más pragmática, la Unidad Fiscal de asistencia en secuestros extorsivos y trata de personas (UFASE) planteaba que la "vulnerabilidad" era una llave que permitía tematizar de manera amplia las inserciones en el mercado sexual como "trata de personas", independientemente del consentimiento que planteara la persona de participar del comercio sexual. El uso de la noción "abuso de situación de vulnerabilidad" que impulsó esta fiscalía especializada permitía minar rápidamente cualquier distinción entre prostitución forzada y libre en los procesos judiciales. Véase Varela (2013).

${ }^{5}$ La ausencia de sistematicidad que podría advertirse como un obstáculo se ve compensada por el hecho de que las sentencias por trata con fines de comercio sexual son publicitadas intensamente por parte de las burocracias judiciales como un modo de exhibir una exitosa política de lucha contra la trata. Burocracias estatales como la Procuradoría de trata y explotación de personas (PROTEX) hace disponible en su sitio web sentencias y produjo recientemente un informe a manera celebratoria de las primeras 100 sentencias obtenidas por trata de personas.
}

Revista Zona Franca- Centro de estudios interdisciplinario sobre las mujeres (CEIM)- Maestría poder y sociedad desde la perspectiva de género (MG), Rosario, Argentina. ISSN, 2545-6504 http://zonafranca.unr.edu.ar/index.php/ZonaFranca| Numero 24 (2016). 
explotación sexual correspondientes a expedientes iniciados en el período 2008-2010 en distintas jurisdicciones del país (ley 26.364). En algunos casos, además de la sentencia, fue posible obtener los autos de procesamiento y otros fragmentos del expediente judicial.

Del corpus construido de sentencias condenatorias por trata de personas (con finalidad de explotación sexual) se desprende que las mujeres representan el $44 \%$ y los varones el $56 \%$ del total de condenados por este delito. Si tenemos en cuenta que la población de mujeres en cárceles del Servicio Penitenciario Federal representa el 8,67 \% de la población carcelaria total $^{6}$, podemos observar que el $44 \%$ representa una alta tasa de criminalización de mujeres ${ }^{7}$. En este sentido, los procesos de criminalización del delito de trata de personas parecen seguir una tendencia similar a los delitos por tráfico de drogas, los cuales muestran una alta tasa de criminalización femenina (Corda, 2011; Giacomello, 2013). El análisis de los expedientes permite observar también que si bien la mayoría de las condenadas son argentinas (64\%), existe un nutrido grupo de paraguayas (29\%) dentro del universo de las mujeres condenadas.

Aunque la retórica que evocan las campañas anti trata se vale de la díada varón-explotador y mujer-víctima inocente, la alta presencia de mujeres entre las condenadas por el delito no ha podido escapar del todo a los activistas antitrata y a las burocracias estatales comprometidas en la campaña. En líneas

\footnotetext{
${ }^{6}$ Elaboración propia sobre la base de datos del Sistema Nacional de Estadísticas sobre ejecución de la pena (SNEEP) y comisión de cárceles de la Defensoría General de la Nación presentados en el libro Mujeres en prisión, CELS; MPDN, 2011. El dato mencionado incluye procesados/as con prisión preventiva y condenados/as en cárceles federales por delitos contra la propiedad, la personas y vinculados al tráfico de drogas y excluye a quienes se encuentren excarcelados/as o con prisión domiciliaria.

${ }^{7}$ Lamentablemente la estadística disponible sobre condenas judiciales no se encuentra desagregada por sexo, lo cual nos impide trazar comparaciones ajustadas con los porcentajes de mujeres condenadas por otros delitos.
}

Revista Zona Franca- Centro de estudios interdisciplinario sobre las mujeres (CEIM)- Maestría poder y sociedad desde la perspectiva de género (MG), Rosario, Argentina. ISSN, 2545-6504 http://zonafranca.unr.edu.ar/index.php/ZonaFranca| Numero 24 (2016). 
generales, las organizaciones anti-trata han evitado problematizar el asunto, pero en algunos eventos anti-trata a los que asistí la alta criminalización de mujeres fue presentada críticamente como una consecuencia de una persecución orientada sobre los "eslabones más bajos de la red" que dejaba intocada a la "grandes mafias que trafican personas". Por otro lado, si bien las burocracias judiciales comprometidas en la persecución penal insisten en la caracterización del delito de trata como un delito de "crimen organizado", en sus informes ha mostrado escenarios más matizados en los cuales los responsables penales por el delito de trata de personas -lejos de organizaciones criminales complejas- resultan de estructuras precarias de ilegalidad de escaso alcance territorial (UFASE, 2013). Desde esta perspectiva, la alta criminalización de mujeres se explica por un proceso de "reconversión de víctimas en victimarias" (Colombo-Mangano, 2013).

En este trabajo intento argumentar que el alto número de mujeres criminalizadas por el delito de trata de personas con fines de comercio sexual se produce en el entrecruzamiento de criminalización primaria y procesos de criminalización secundaria. Las perspectivas criminológicas críticas han mostrado que el proceso de criminalización no se agota en la sanción de normas. Mientras la criminalización primaria alude a la creación de normas penales, los procesos de criminalización secundaria refieren a la selección por parte de las burocracias estatales respecto de qué ilegalismos serán finalmente perseguidos y qué sujetos pueden ser criminalizados (Baratta, 1989; Pavarini, 1990). En virtud de la selectividad con la que operan las agencias del sistema penal, la criminalización secundaria solo alcanza a una parte de las actividades cuya persecución es prevista por el programa político-criminal. 
Así, en primer lugar, la amplitud del tipo penal definido en la ley 26.364 y 26.842 permite potencialmente criminalizar a los dueños de los establecimientos y a los colaboradores de los procesos migratorios hacia el mercado sexual, pero también a las "terceras partes" como recepcionistas y encargadas. A partir de la intensidad que fue adquiriendo la campaña anti-trata en el contexto local y la ambigüedad del tipo penal, el delito de "trata de personas" fue desprendiéndose de su original asociación con los procesos migratorios y en muchos casos desplazó a los delitos de "proxenetismo" y "promoción de la prostitución"8. Así, en una entrevista un operador judicial de un juzgado federal me explicaba el potencial del tipo penal para capturar distintas situaciones en el mercado sexual: "acoger es estar en el lugar". Este estilo de interpretaciones fue paulatinamente habilitando la criminalización bajo el delito de "trata de personas" - de un conjunto de trabajos que resultan necesarios para el desarrollo del comercio sexual, pero que no resultan reductibles a la posición de los llamados "reclutadores" o los dueños de las explotaciones comerciales. Muchas mujeres permanecen en el mercado sexual como recepcionistas y encargadas de departamentos privados o whiskerías, cuando no desarrollan sus propios emprendimientos. En contraste con la visión dicotómica entre explotadores varones e inocentes mujeres, propia de las retóricas anti-trata, las mujeres se encuentran activamente involucradas en el comercio sexual en función del desarrollo de sus propias carreras comerciales. En la primera parte, a partir del análisis del corpus de causas judiciales y entrevistas, busco reconstruir algunos aspectos de la lógica de estas carreras y sugiero que la reducción de estas trayectorias a un proceso de "reconversión

\footnotetext{
${ }^{8}$ Otras investigaciones han observado ese mismo desplazamiento. Véase INECIP 2013.
}

Revista Zona Franca- Centro de estudios interdisciplinario sobre las mujeres (CEIM)- Maestría poder y sociedad desde la perspectiva de género (MG), Rosario, Argentina. ISSN, 2545-6504 http://zonafranca.unr.edu.ar/index.php/ZonaFranca| Numero 24 (2016). 
de víctimas en victimarias" hecha poca luz sobre el nudo de relaciones a partir de las que las mujeres se insertan y permanecen en el mercado sexual.

En segundo lugar, la criminalización de mujeres puede reforzarse por los procesos de criminalización secundaria. Las perspectivas criminológicas críticas han subrayado los mecanismos de selección negativa que hacen que una minoría de los sujetos en infracción con la ley penal, aquellos que pertenecen a las clases sociales o grupos más desventajados, sea reconocidos como criminales $^{9}$. Bajo esta idea, en la segunda parte, exploro los procesos de reacomodamiento del mercado de departamentos privados de la CABA en el contexto del despliegue de las políticas anti-trata y sugiero que las estrategias de movilidad social ascendente puestas en marcha por muchas trabajadoras sexuales fueron criminalizadas, mientras que los dueños de los establecimientos lograron delinear estrategias que los colocaron a resguardo de la persecución penal. A través de mi trabajo de campo intento mostrar que la criminalización de mujeres puede reforzarse por los procesos de criminalización secundaria, pero sugiero que esta selectividad no funciona de manera prístina y autoevidente, definiendo a priori como objeto de persecución a las mujeres. En cambio, esa selectividad se produce en mercados de trabajo atravesados por desigualdades de género y clase, y por circuitos de criminalización complejos, los cuales necesitan ser ponderados y analizados en contextos específicos.

\footnotetext{
${ }^{9}$ Por su parte, los estudios sobre sexo comercial han puesto de relieve cómo las normas penales se utilizan sobre determinadas formas del sexo comercial, mientras que otras permanecen largamente ignoradas (Agustín, 2008). En el contexto argentino, un conjunto amplio de formas de inserción en el mercado sexual potencialmente criminalizables por la legislación actual (tales como las web cammers o la pornografía con arreglos que involucran terceros) resultan ignoradas y la persecución se orienta sobre la prostitución en departamentos privados y whiskerías.
}

Revista Zona Franca- Centro de estudios interdisciplinario sobre las mujeres (CEIM)- Maestría poder y sociedad desde la perspectiva de género (MG), Rosario, Argentina. ISSN, 2545-6504 http://zonafranca.unr.edu.ar/index.php/ZonaFranca| Numero 24 (2016). 


\section{Carreras en el sexo comercial}

En nuestro país la investigación sobre mercados sexuales es incipiente y disponemos de pocos trabajos empíricos que permitan caracterizar las formas de organización del mercado sexual en el contexto local ${ }^{10}$. A su vez, las investigaciones sobre sexo comercial enfrentan grandes obstáculos técnicometodológicos: la ilegalidad de la explotación de la prostitución ajena, el carácter clandestino y no regulado del mercado del sexo, el estigma asociado a los intercambios de sexo/dinero y la inserción predominante en estos mercados de migrantes en situación precaria. Dentro de este marco y aun con sus limitaciones, los expedientes judiciales constituyen una fuente de información que permite trazar de manera exploratoria un panorama que necesita en el futuro ser complejizado por otras modalidades de investigación empírica. En este sentido, mi propia lectura de las causas judiciales fue enriquecida por las entrevistas realizadas a mujeres involucradas en el mercado sexual y el desarrollo de un trabajo de campo en el circuito de los departamentos privados de la CABA durante el 2013. Así, esta combinación de estrategias permite describir algunos de los contextos más habituales de oferta/demanda de servicios sexuales puertas-adentro, los procesos de organización del trabajo en ellos, las modalidades de inserción y permanencia en el mercado y las trayectorias de las personas que ofrecen sexo comercial y/o desarrollan emprendimientos en este mercado. Especialmente, nos interesa explorar estas

\footnotetext{
${ }^{10}$ Los trabajos de Morcillo $(2011,2014 a)$ han relevado las tácticas que despliegan y las formas de identificación de las mujeres que realizan sexo comercial en el contexto local. Otros trabajos han abordado la migración de mujeres dominicanas y su inserción en el mercado sexual (OIM, $2003,2015)$ y las formas de gobierno sobre el mercado sexual (Sirimarco-Daich, 2014, DaichVarela, 2014)
}

Revista Zona Franca- Centro de estudios interdisciplinario sobre las mujeres (CEIM)- Maestría poder y sociedad desde la perspectiva de género (MG), Rosario, Argentina. ISSN, 2545-6504 http://zonafranca.unr.edu.ar/index.php/ZonaFranca| Numero 24 (2016). 
cuestiones a los fines de comprender el alto porcentaje de mujeres condenadas en causas por delito de trata de personas.

Vale mencionar en primer lugar que las modalidades de inserción popularmente asociadas a la "trata" -mujeres retenidas contra su voluntad a través de coacciones extraeconómicas- configuran una minoría entre las causas judiciales analizadas. También configuran un pequeño número aquellos procesos judiciales que criminalizan prácticas que no podrían haber sido perseguidas por la legislación anterior, tales como la figura del "reclutador" desvinculado de la explotación comercial. Los dispositivos penales capturan más bien una serie de formas de proxenetismo, si entendemos por proxenetas a "aquellas personas que juegan un rol activo e identificable en la reproducción cotidiana de una o más personas que hacen prostitución" (O’Connel Davidson, 1998: s/p). La figura estereotipada (y masculinizada) del proxeneta no permite dar cuenta de la variedad de roles y posiciones que permiten la reproducción cotidiana de las personas que ofertan sexo comercial. Por ello, O' Connel Davidson (1998) propone analizar "patrones de proxenetismo" que permiten diferenciar entre quienes ejercen una forma de control directo sobre las prostitutas y quienes desarrollan alguna función identificable y reciben un pago en intercambio por estos servicios (o quienes combinan algunas de estas dos formas).

Una gran parte de las whiskerías y cabarets identificados en el marco de las causas judiciales que analicé constituyen emprendimientos de pequeña escala desarrollados por una pareja con una clara división sexual del trabajo. Mientras el varón se encarga de la relación con la policía y otros agentes 
estatales (como inspectores municipales), provee seguridad y atiende a la infraestructura del negocio, las mujeres se ocupan de administrar los servicios de bar, organizar el trabajo y eventualmente el alojamiento de las mujeres que ofrecen sexo comercial en el lugar. Las tareas de cobro por los servicios sexuales pueden encontrarse alternativamente a cargo de uno $u$ otro. Frecuentemente, estas mujeres tuvieron una inserción previa en el mercado sexual como trabajadoras y desarrollaron en este espacio vínculos matrimoniales que se ligaron con su participación -con distintos grados de autonomía- de emprendimientos de sexo comercial. Muchas de las formas de organización de la oferta de servicios sexuales identificadas en el análisis de las causas judiciales pueden ser comprendidas a través del concepto de "proxenetismo de emprendedor" propuesto por O'Connel Davidson (1998), si agregamos a su vez que los arreglos matrimoniales y los lazos de parentesco juegan un papel crucial en la organización de este tipo de negocios ${ }^{11}$. Este concepto busca capturar aquellas formas de proxenetismo en las cuales predomina la provisión de servicios (y no las coacciones extraeconómicas) y que habitualmente involucra a personas que tuvieron una inserción previa en el mercado como trabajadoras y desde allí experimentan el desarrollo de un propio negocio como una forma de "ascenso social".

Muchas mujeres procesadas y condenadas en las causas judiciales se desempeñaban como "terceras partes", tal como la figura de la "recepcionista" en los departamentos privados. A diferencia de las whiskerías y cabarets, estos departamentos ubicados en centros urbanos no se encuentran abiertos al

\footnotetext{
${ }^{11}$ Las otras formas de proxenetismo descriptas por la autora son: el proxenetismo callejero, el sexo de sobrevivencia en contextos de extrema pobreza, el proxenetismo como forma de extensión del abuso sexual, y el proxenetismo por parientes.
}

Revista Zona Franca- Centro de estudios interdisciplinario sobre las mujeres (CEIM)- Maestría poder y sociedad desde la perspectiva de género (MG), Rosario, Argentina. ISSN, 2545-6504 http://zonafranca.unr.edu.ar/index.php/ZonaFranca| Numero 24 (2016). 
público y a ellos se accede mediante una cita previa concertada telefónicamente. En estos casos, la recepcionista es quien recibe los llamados telefónicos y ofrece los servicios, recibe y despide a los clientes, organiza la limpieza del lugar, cobra las tarifas, distribuye el dinero de acuerdo a los arreglos pactados y finalmente entrega la recaudación final al dueño/a. Si el lugar combina trabajo/vivienda, la recepcionista o encargada puede también ocuparse de administrar la organización de la casa. La presencia del dueño puede ser más o menos visible, como trataremos más adelante. Los arreglos económicos son variables: la mayoría de las recepcionistas cobra un porcentaje de las ganancias diarias y las menos cobran un monto preestablecido. Muchas "recepcionistas" son ex trabajadoras sexuales de mediana edad que ya se han desplazado hacia otras modalidades de inserción en el mercado, mientras que todavía conservan algunos clientes denominados "fijos" con los cuales eventualmente realizan servicios.

Las posiciones en el mercado son variables, pueden alterarse en el tiempo tanto como combinarse. Jessica, a quien entrevisté en su departamento de la zona de tribunales, se balanceaba con destreza e inventiva en un mundo de pocas previsibilidades. A sus cuarenta años tenía 6 hijos y un ex marido preso por tráfico de drogas, lo cual la dejaba como único sostén económico de su familia. Había logrado convertirse en "dueña" del departamento que visité luego de que el propietario anterior, preocupado por la persecución penal en la CABA, buscara desentenderse del mismo. Durante el día seguía ofreciendo servicios sexuales en el departamento y se quedaba también con el $50 \%$ de las ganancias de las restantes 3 o 4 trabajadoras que alternativamente 
brindaban servicios el lugar. Por las noches, trabajaba como "recepcionista" en un departamento privado de otro dueño. Así combinaba su propia oferta de servicios sexuales, con la explotación de los servicios brindados por otras trabajadoras y su trabajo como recepcionista en otro lugar. Su proyecto de retiro era utilizar el dinero que había podido ahorrar para abrir una panadería en la que trabajaría su ex marido, una vez que saliera de la cárcel. Allí planeaba replicar el mismo arreglo económico que sostenía con las trabajadoras sexuales del lugar que administraba: $50 \%$ de las ganancias cada parte.

Algunos departamentos privados -a diferencia de las whiskerías y cabarets frecuentemente organizados por una pareja- resultan de iniciativas de ex o actuales trabajadoras sexuales por fuera de un arreglo matrimonial. Sin embargo, las trabajadoras en ocasiones hacen uso de sus vínculos con clientes para construir este tipo de emprendimientos. Así, Pablina y Clara, dos hermanas paraguayas a quienes entrevisté durante su prisión preventiva, se habían apoyado en la relación romántica que una de ellas mantenía con un cliente para lograr manejar su propio departamento ${ }^{12}$. El estigma que pesa sobre los intercambios de sexo por dinero y las redes de ocultamiento que las mujeres tejen trabajosamente en relación a su inserción en el mercado frente a sus parejas y familias, sumado a la condición de migrantes de muchas de ellas, hace frágiles los capitales sociales. Por ello, los clientes emergen en muchas ocasiones como la red más cercana que puede ayudar a resolver el acceso a un aborto, escapar de un empleador abusivo tanto como abrir un negocio

\footnotetext{
${ }^{12}$ Morcillo (2013) analiza en el contexto local las relaciones de las mujeres que hacen sexo comercial con los clientes-amigos y los amantes-renta y la circulación de bienes económicos en estas relaciones.
}

Revista Zona Franca- Centro de estudios interdisciplinario sobre las mujeres (CEIM)- Maestría poder y sociedad desde la perspectiva de género (MG), Rosario, Argentina. ISSN, 2545-6504 http://zonafranca.unr.edu.ar/index.php/ZonaFranca| Numero 24 (2016). 
propio. En este caso, esta estrategia había permitido salvar los problemas relativos a la inversión inicial y la garantía requerida para el alquiler de un departamento, difícilmente accesible para un migrante de sectores subalternos. Finalmente, un conflicto con una de las trabajadoras por las condiciones de trabajo y los arreglos económicos pactados desencadenó una denuncia por trata de personas y Pablina y Clara fueron detenidas.

El análisis de los expedientes judiciales y las trayectorias que describí hasta aquí muestran que la dicotomía víctima/victimario no permite reflejar las múltiples posiciones que adoptan las mujeres en el mercado sexual ni la complejidad de sus trayectorias. Casos como el de Jessica muestran que las trabajadoras pueden combinar más de una modalidad de inserción (trabajadora, tercera parte y dueña al mismo tiempo). También, como Pablina y Clara, las trabajadoras pueden desplazarse entre una y otra posición en el mercado a lo largo del tiempo, sopesando alternativas y oportunidades y tejiendo trabajosamente proyectos de movilidad social desde posiciones de subalternidad.

Brewis y Linstead (2000) han propuesto el concepto de "carrera comercial" para comprender este tipo de trayectorias en el mercado sexual. El declinamiento del capital erótico a lo largo de los años fuerza a buscar rápidas alternativas, opciones entre las cuales se encuentra desarrollar su propio negocio o administrar el de un tercero en el mercado del sexo comercial. La idea de "conversión de víctimas en victimarias" presenta los modos de vida y experiencias de las trabajadoras sexuales de sectores subalternos como la paradójica consecuencia de un pasado traumático que sólo pueden reproducir 
a través del ejercicio de la violencia sobre otras mujeres. Esta perspectiva - a la vez que las responsabiliza por situaciones estructurales de opresión de otras mujeres- no permite capturar las tácticas que ellas despliegan y que redundan en ocasiones en una simultánea inserción en el mercado como "explotadas"/víctimas (como trabajadoras) y "explotadoras"/victimarias (en tanto dueñas de emprendimientos de sexo comercial), a la vez que oscurece la especificidad de posiciones en el mercado no reductibles a la dicotomía victimizante (tales como las terceras partes). Comprender este tipo de inserciones en el mercado como el producto de una trayectoria social, permite pensar que las posiciones de clase (y los capitales asociados a ellas) se asocian a un haz limitado de trayectorias posibles donde se expresan las disposiciones del habitus (Bourdieu, 2000). Desarrollar el propio emprendimiento de sexo comercial o proveer servicios como tercera parte conforma parte del horizonte de expectativas de quienes se insertan en el mercado sexual y es vivido como una forma de ascenso social. La percepción de la rápida pérdida del capital erótico a lo largo de los años y la ausencia de sistemas de seguridad social que permitan hacer frente al envejecimiento introduce presiones que sólo aceleran la búsqueda de otras modalidades de inserción en el mercado.

Finalmente, los dispositivos penales traducen el nudo complejo de relaciones de subalternidad a través de las cuales las mujeres se insertan y desarrollan carreras en el mercado sexual en una ecuación rígida entre víctimas y victimarios, entendidos éstos últimos como individuos portadores de intencionalidades precisas. Mientras la dicotomía varón-explotador/mujer- 
inocente predomina en la narrativa anti-trata, los procesos judiciales avanzan en la criminalización de mujeres como hemos mostrado a partir del análisis de la distribución de sentencias condenatorias y analizamos en el siguiente caso.

\section{Teresa: vulnerabilidad y ascenso social}

Además de recepcionistas y emprendedoras de sus propios negocios, las trabajadoras sexuales funcionan también como facilitadoras de contactos entre sus redes familiares y de conocidos. Por intermedio de una conocida, Teresa con sus 23 años había llegado desde Paraguay para trabajar en un departamento privado de una ciudad balnearia. La entrevisté luego haber leído su causa judicial, cuando cumplida parte de su condena por trata de personas pudo acceder al beneficio de la prisión domiciliaria. Su historia comenzaba con el arribo a un departamento privado de la ciudad en el cual el dueño proveía el alojamiento y cerca de 8 trabajadoras se organizaban en turnos de 12 horas. Como era muy común, el dueño utilizaba a su favor el desconocimiento de las leyes migratorias para ejercer un mayor control sobre las trabajadoras. Así, la había prevenido de salir del lugar, bajo la advertencia de que en la calle podrían detenerla por "no tener documento argentino". Un conflicto con el dueño y el apoyo de un cliente hicieron que Teresa percibiera que estas amenazas poco tenían que ver con las condiciones de la población migrante en la Argentina y abandonara el lugar. Semanas después, en sociedad con este cliente y un socio más, habían montado un nuevo departamento a pocas cuadras de la playa. Mientras Teresa seguía ofreciendo servicios sexuales, comenzó a proponerles a sus ex compañeras que se fueran a trabajar con ella. La nueva casa ofrecía mejores condiciones y arreglos económicos más 
beneficiosos para las trabajadoras. No sólo algunas de sus ex compañeras fueron a trabajar al nuevo departamento, sino que también llegaron otras jóvenes mujeres por intermedio de redes de conocidas y parientas desde Paraguay. Habían pasado solo 3 meses y Teresa ya trabajaba como recepcionista en un departamento en el que vivían y ofrecían servicios sexuales 10 trabajadoras. En agosto del 2008 el lugar fue allanado a través de una serie de operativos impulsados por la justicia federal local, y Teresa fue detenida junto a uno de los dueños. Las trabajadoras siguieron ofreciendo servicios sexuales en el lugar y se presentaron a declarar en el juzgado manifestado su deseo de permanecer trabajando y residiendo en la casa. Algunas de ellas contaron haber mejorado su situación en relación a inserciones anteriores en el mercado sexual (en otros departamentos privados de la ciudad donde no se les permitía salir y se les cobraba distintas penalidades) y también respecto de otros trabajos precarios (como trabajadoras de casas particulares). De hecho, según relatan, el emprendimiento actual había surgido de la voluntad de algunas de ellas, encabezadas por Teresa, para "buscar una casa en donde pagaran todas juntas y en la que no hubiera ni dueño, ni encargado". En sus declaraciones en el expediente judicial dan cuenta de su preocupación por la situación Teresa, a quien han visitado en el penal en que se encontraba detenida.

Lejos de las potencialidades que las trabajadoras percibían en su propio proceso migratorio e inserción en el mercado, el juez -considerando la existencia de un "abuso de situación de vulnerabilidad"- decreta el procesamiento de los imputados en la causa. Pocos días después, la defensa 
adjunta al expediente una declaración realizada por las trabajadoras frente a un escribano en donde -en algún intento de generar legalidad "desde abajo"declaraban "que de ninguna manera consideramos estar en situación de vulnerabilidad, explotadas y/o en estado de servidumbre como se nos quiere hacer creer. Nunca antes de ahora hemos estado y vivido mejor". El caso alcanza su resolución mediante un juicio abreviado en el cual los imputados se hacen responsables por el delito de trata de una menor de edad de 17 años y nueve mujeres paraguayas mayores mediando "abuso de situación de vulnerabilidad"13. Hacia el final del fallo se reconoce que:

...por problemas y negligencias investigativas se termina puniendo a los autores menos importantes de la cadena de trata, como es exactamente el caso de autos, donde nos encontramos con un no vidente y con una mujer tratada que ascendió de categoría y pasó a ser la regente de sus propias compañeras, nuevas víctimas

Así, cuando una mujer que ha padecido las mismas situaciones de "vulnerabilidad" que las consideradas "víctimas" es identificada como tercera parte, dueña o facilitadora de contactos en una causa por trata de personas, se convierte para el dispositivo judicial en la responsable criminal, a la cual no corresponde protección legal o asistencial alguna. Las condiciones de "vulnerabilidad" que construyen a una "víctima" del delito de trata, pierden toda relevancia en el marco de los procesos judiciales cuando una mujer facilita

\footnotetext{
${ }^{13}$ La sentencia dice lo siguiente: "De los relatos efectuados por las víctimas mayores de edad en sede judicial, se desprende que las mismas compartían una idiosincrasia común, provenientes de familias de escasos recursos, apremiadas por la situación económica de su país encontraron trabajo como empleadas domésticas, necesitando dinero para sostener a sus familias, en su mayoría numerosas, con hijos menores de edad para criar, aceptaron venir a ejercer la prostitución como una opción para obtener dinero y enviarlo a sus familiares. Surge en autos que esta situación no era desconocida por los encartados, quienes se aprovecharon de la vulnerabilidad socioeconómica y familiar de las nombradas con la finalidad de explotarlas mediante el facilitamiento del ejercicio de la prostitución."
} 
contactos dentro de su red de parientas y conocidas o bien obtiene posiciones que son percibidas como una ascenso social o reaseguro frente a la vejez

Si bien la ley 26.364 establece en su artículo 5 que "las víctimas de trata no son punibles por la comisión de cualquier delito que sea el resultado director de haber sido objeto de trata" y que de acuerdo a las interpretaciones consagradas de la ley prácticamente cualquier mujer en el mercado sexual puede ser considerada una víctima de trata, el corpus de causas judiciales analizado muestra que esta herramienta legal no ha sido utilizada para descriminalizar este tipo de trayectorias en el mercado. ${ }^{14} \mathrm{~A}$ su vez, del análisis de las penas de prisión otorgadas se desprende que varones y mujeres obtienen similares condenas (ver Varela-Gutiérrez, 2015).

\section{Explotación: entre la economía política y el derecho}

En el año 2013 realicé trabajo de campo en un segmento del circuito del sexo comercial de la Ciudad de Buenos Aires, específicamente en los departamentos privados en los cuales se ofrecen servicios sexuales de menor precio del mercado. La reforma de la ley de trata en diciembre del 2012 había traído aparejado un intenso despliegue de las burocracias judiciales y los inspectores municipales con el fin de cerrar cualquier lugar en el que se ofreciera sexo comercial. No se trataba solamente de una operación de policía, sino que también existían fuertes presiones para lograr condenas por trata de

\footnotetext{
${ }^{14}$ La única excepción es una causa en la cual la considerada "víctima" de trata fue absuelta del delito de aborto.
}

Revista Zona Franca- Centro de estudios interdisciplinario sobre las mujeres (CEIM)- Maestría poder y sociedad desde la perspectiva de género (MG), Rosario, Argentina. ISSN, 2545-6504 http://zonafranca.unr.edu.ar/index.php/ZonaFranca| Numero 24 (2016). 
personas. Mientras el gobierno nacional se había ya comprometido con la campaña, Buenos Aires -centro del poder político y económico del paíscarecía de condenas este delito. Lejos ya del contexto de las discusiones iniciales del año 2008, la trata de personas se había transformado en un problema autoevidente en su asociación directa con la prostitución y de allí parecía deducirse de manera lineal que a mayor densidad poblacional, más "redes de trata" operando debían suponerse.

La creciente presión penal produjo una serie de reconfiguraciones en el mercado. Me interesa detenerme en las estrategias que los "dueños" de los departamentos privados pusieron en marcha para terciarizar los emprendimiento bajo distintas modalidades. En primer lugar, es necesario decir que la categoría "dueño" es sumamente equívoca. En la cotidianeidad del trabajo sexual la palabra "dueño" generalmente es empleada para referirse a quien organiza los turnos, resuelve la limpieza, publicita el lugar, establece los arreglos con las trabajadoras, negocia con la policía e inspectores municipales y recolecta el porcentaje acordado de las ganancias de las trabajadoras. En algunos casos el "dueño" puede estar presente en el lugar de trabajo y ocuparse de cobrar a los clientes y en otras ocasiones puede delegar algunas de esas tareas en una encargada/recepcionista. En este sentido, el "dueño" puede no coincidir con el titular del inmueble (a quien alquila la propiedad). Este "dueño" del emprendimiento (equivalente a un titular de fondo de comercio) puede a su vez subalquilar el negocio a un segundo "dueño", produciéndose cadenas de subarrendamiento como veremos a continuación. 
Dueño del inmueble, dueño del emprendimiento, dueño-encargado son distintas posiciones que pueden no coincidir en la misma persona.

A comienzos del año 2013, luego del fallo por el caso Marita Verón y la modificación de la ley de trata, comenzaron a dispararse cotidianamente una serie de operativos sobre los departamentos privados de la ciudad de Buenos Aires. El despliegue de los allanamientos había alterado los otrora márgenes de tolerancia en torno al comercio sexual, y convertido especialmente en peligrosa la situación para los dueños varones quienes eran identificados mucho más rápidamente como proxenetas. Así, algunos de ellos buscaron la manera de desprenderse de sus responsabilidades sobre la explotación mediante una estrategia de terciarización: ofrecían en alquiler (o en subalquiler) la propiedad a una trabajadora sexual, quien de ahí en adelante asumía el emprendimiento por cuenta propia y establecía con las otras trabajadoras arreglos económicos que habitualmente suponían una comisión del $50 \%$ de sus ganancias. Muchas trabajadoras sexuales vieron llegar allí su oportunidad para lograr cierta movilidad ascendente y construir su propio emprendimiento. Los precios que los dueños (de la propiedad o del "fondo de comercio") cobraban por los alquileres triplicaban los precios habituales del mercado inmobiliario, pero no exigían los requisitos habituales que difícilmente podían cubrir trabajadores informales (como proporcionar una propiedad en garantía o acreditar una fuente de ingresos) y garantizaban la posibilidad de desarrollar un emprendimiento de sexo comercial. Además, no cualquier departamento es lo suficientemente conveniente para hacer sexo comercial: es necesario vecinos discretos (o edificios donde trabajan profesionales habituados al entrar y salir 
de gente), un portero amigable, o simplemente una puerta con salida a la calle que no genere problemas con los vecinos.

A través de esta estrategia de terciarización algunos dueños lograron mantener sus ganancias disminuyendo los riesgos que la presión del sistema penal ocasionaba. De ahí en más, frente a la investigación judicial y el allanamiento, quedarían resguardados bajo un contrato de alquiler, mientras que las ex trabajadoras devenidas "dueñas" cargarían con la presión judicial. Lo que me interesa aquí señalar es que el concepto de "explotación sexual" o "explotación de la prostitución ajena" asigna responsabilidades entre individuos que son -en mayor o menor medida- empíricamente observables en el espacio de trabajo. Es decir, identifica que $A$ explota a $B$ en tanto y en cuanto $A$ retiene un porcentaje de las ganancias de B. Este esquema prístino -apoyado sobre la idea de individuos libres e iguales del contrato social- se topa con una serie de complejidades si observamos la conformación del mercado sexual desde el punto de vista de la economía política. Así, si una ex trabajadora -ahora devenida dueña- retenía el $50 \%$ de las ganancias pasaba a ser responsable jurídicamente, independientemente que gran parte de la facturación fuera a parar a los bolsillos del dueño del departamento, ahora protegido por un contrato de alquiler entre partes consideradas iguales. El término "explotación" -tal como es operacionalizado por las burocracias judiciales- no coincide con lo que consideraríamos "relaciones de explotación" desde el punto de vista de la economía política, es decir, la relación capital-trabajo. Los dueños pudieron, en este sentido, articular sus saberes sobre las lógicas del mercado y el nuevo 
contexto político con el lenguaje legal para generar una estrategia de protección con una mínima pérdida de ganancias.

En este camino, las trabajadoras sexuales de mediana edad que no disponían de suficientes capitales (económicos y sociales) para desarrollar sus propios emprendimientos, percibieron la posibilidad de lograr una movilidad ascendente. Esta oportunidad de convertirse en "dueñas" con una baja inversión tenía como contraparte el riesgo cada vez mayor de su criminalización. El aislamiento de las trabajadoras sexuales derivado de las condiciones de clandestinidad y estigmatización en que se desarrolla el comercio sexual, la debilidad de sus formas de organización (en comparación con otros trabajadores de la economía formal) y su falta de conocimiento del contexto legal y político hizo que en muchos casos no percibieran con precisión los riesgos que esta potencial estrategia de movilidad social comportaba en el nuevo contexto político.

\section{Palabras finales}

Si los únicos términos posibles de una relación social son los de "víctima" o "victimario", el lenguaje del derecho penal -convertido ya en teoría de lo social -desplaza la comprensión de las experiencias de opresión de los sujetos a la luz de los procesos y dinámicas sociales que las producen. Muchas veces los factores que hacen que una persona desarrolle un emprendimiento de sexo comercial son las mismas condiciones de pobreza, vulnerabilidad y ausencia de sistemas de protección social que llevaron a una persona a ofrecer servicios sexuales. A su vez, esta perspectiva punitiva obtura el análisis de las 
modalidades heterogéneas de inserción y permanencia en el mercado, las trayectorias sociales y los horizontes de expectativas a partir de los cuales las trabajadoras sexuales construyen sus proyectos de movilidad social. Así, un análisis de las modalidades de inserción de las mujeres en el mercado sexual requiere ponderar simultáneamente su agencia tanto como las condiciones de subalternidad a través de las cuales sus carreras comerciales se proyectan.

La campaña anti-trata en la Argentina ha privilegiado el sistema punitivo como herramienta para abordar los problemas de desigualdad social y de género en el mercado. Como intenté mostrar a través del análisis de la alta criminalización de mujeres por el delito de trata y los procesos de reacomodamiento del mercado, es posible que el sistema punitivo, más que minar esas desigualdades y jerarquías, en su despliegue práctico termine por reproducirlas y profundizarlas. Las operaciones concretas de las burocracias judiciales no se producen en un vacío -donde pudieran desarrollarse con toda facilidad los proyectos bienintencionados de los rescatistas- sino en un espacio social complejo atravesado por desigualdades, estigmatización y donde juegan sus cartas distintas fuerzas.

En este contexto, una imaginación no punitiva puede permitirnos pensar en alternativas que contemplen las experiencias de los sujetos, sus atravesamientos múltiples por distintas formas de opresión, y -a la luz de elloconstruir intervenciones que amplíen los márgenes de autonomía en contextos específicos. En primer lugar, esto requiere atender a las desigualdades económicas y sociales que enfrentan las mujeres de sectores subalternos para su reproducción y la de sus familias a través de políticas sociales y de 
redistribución del ingreso. En lo que hace a las mujeres que se encuentran en el comercio sexual es necesario reconocer los efectos del doble movimiento de "pinzas" que hemos intentado describir: por un lado, la lógica del mercado que las impulsa a participar de emprendimientos de sexo comercial en ausencia de sistemas de seguridad social y por otro lado, el sistema penal que las criminaliza al acudir al rescate de otras mujeres si llegaran a hacerlo. Esta compresión que necesitamos agudizar -lejos de los lenguajes legales- puede edificarse sobre el corpus de herramientas que el feminismo ha elaborado históricamente para pensar las opresiones específicas de las mujeres.

\section{Bibliografía}

AGUSTÍN, Laura (2008) "Sex and the limits of enlightenment: the irrationality of legal regimes to control prostitution", en Sexuality research and social policy, V. 5, N4, pp. 73-86

BARATTA, Alessandro (1989) Criminología crítica y crítica del derecho penal, Siglo XXI, México

BODELON, Encarna (1998) "El cuestionamiento de la eficacia del derecho en relación a la protección de los intereses de las mujeres", en Revista Delito y Sociedad, $\mathrm{N}^{\circ} 11$ y 12 , pp.125-137

BOURDIEU, Pierre (2000) La distinción. Criterio y bases sociales del gusto, Taurus, Madrid

BREWIS Joanna y LINSTEAD, Stephen (2000) "The worst thing is the screwing (2): context and career in sex work", en Gender, work and organization, V. 7, $\mathrm{N}^{\circ} 3$, pp. 163-172

CAREF - OIM (2015) La migración dominicana en Argentina. Trayectorias en el nuevo siglo, Buenos Aires

CENTRO DE ESTUDIOS LEGALES Y SOCIALES (CELS) (2011) Mujeres en prisión. Los alcances del castigo, Siglo XXI, Buenos Aires

COLOMBO, Marcelo y MANGANO, María (2013) "Sobre víctimas victimarias". En INECIP (ed) ¿Qué hicimos con la trata?, INECIP, Buenos Aires

COHEN, Stanley (1985) Visiones del control social, Polity Press, Oxford 
CORDA, Alejandro (2011) Encarcelamientos por delitos relacionados con estupefacientes en Argentina Intercambios Asociación Civil, FSOC-UBA

DAICH, Deborah, SIRIMARCO, Mariana (2014) Policías y prostitutas: el control territorial en clave de género, Revista Publicar, Año 12, N 17, pp.27-45

DAICH, Deborahy VARELA, Cecilia (2014) "Entre el combate a la trata y la criminalización del trabajo sexual: las formas de gobierno de la prostitución", en Delito y Sociedad, $\mathrm{N}^{\circ}$ 38, pp. 63-86

DOEZEMA, Jo (2010) Sex slaves and discourse masters. The construction of trafficking, Zed Books, London.

GARCÍA MENDEZ; Emilio, ASPRELLA, Eva y PLOSKENOS, Analía. (2008) "El problema del consentimiento en el delito de trata de personas". En Isla, María y Demarco, Laura (comp.) Se trata de nosotras (pp. 281-296), Las Juanas editoras, Buenos Aires

GIACOMELLO, Corina (2013) Mujeres, delitos de drogas y sistemas penitenciarios en América Latina, Consorcio Internacional sobre Políticas de Drogas, RandomHouse, Mondadori

GULCUR, Leyla y ILKKARACAN, Pinar (2002) "The "Natasha" experience: migrante sex workers from the former soviet union and eastern Europe in Turkey", en Women's studies International Forum, V. 25, № 4, pp.11421

INSTITUTO DE ESTUDIOS COMPARADOS EN CIENCIAS PENALES Y SOCIALES (INECIP) (2013) ¿Qué hicimos con la trata? Un recorrido por las principales políticas públicas de trata sexual en Argentina, La Plata. Barcelona

JULIANO, Dolores (2002), La prostitución: el espejo oscuro, Icaria,

LARRAURI, Elena (1994) "Control formal: ...y el derecho penal de las mujeres". En Larrauri, Elena (comp.) Mujeres, derecho penal y criminología. (pp. 93-108), Siglo XXI, México

MORCILLO, Santiago (2011) "De cómo vender sexo y no morir en el intento. Fronteras encarnadas y tácticas de quienes trabajan en el mercado sexual", en Revista Latinoamericana de Cuerpos Emociones y Sociedad, V. 7, $\mathrm{N}^{\circ} 3$, pp. $17-28$

MORCILLO, Santiago (2013) Sexo por dinero: tensiones y negociaciones cotidianas según los relatos de mujeres que hacen sexo comercial en Buenos Aires, Tesis de doctorado FSOC-UBA, San Juan y Rosario 
MORCILLO, Santiago (2014a) "'Como un trabajo'. Tensiones entre sentidos de lo laboral y la sexualidad en mujeres que hacen sexo comercial en Argentina", en Sexualidad, Salud y Sociedad (Rio de Janeiro), № 18, pp. 12-40

O'CONNEL DAVIDSON, Julia (1998) Prostitution, power and freedom, Polity Press, Cambridge

OIM (2003) Migración, prostitución y trata de mujeres dominicanas en la Argentina, Buenos Aires

PAVARINI, Massimo (1980) Control y dominación. Teorías criminológicas burguesas y proyecto hegemónico, Siglo XXI, México

PHETERSON, Gail (1996), Mujeres en flagrante delito de independencia, Ballaterra, España

PISCITELLI, Adriana (2008) "Entre as "máfias" e a "ajuda" a construção de conhecimento sobre tráfico de pessoas", en Cadernos Pagu, V. 31, pp. 2937

PITCH, Tamar. (1995) Responsabilidades limitadas. Actores, conflictos y justicia penal, Ad-Hoc, Buenos Aires

PROCURADORÍA DE TRATA Y EXPLOTACIÓN DE LAS PERSONAS, (2015) Informe sobre las primeras cien sentencias condenatorias por trata de personas.

UNIDAD FISCAL DE ASISTENCIA EN SECUESTROS EXTORSIVOS Y TRATA DE PERSONAS (UFASE) - INSTITUTO DE ESTUDIOS COMPARADOS EN CIENCIAS PENALES Y SOCIALES (INECIP) (2012) La trata sexual en Argentina. Aproximaciones para un análisis de la dinámica del delito, Buenos Aires.

VARELA, Cecilia (2012), "Del tráfico de las mujeres al tráfico de las políticas. Apuntes para una historia del movimiento anti-trata en la Argentina (1998-2008)", en Revista Publicar. Colegio de graduados de antropología, Año X, N ${ }^{\circ}$ XII, pp. $35-64$

(2013) "De la "letra de la ley" a la labor interpretante: la "vulnerabilidad" femenina en los procesos de judicialización de la ley de trata de personas (2008-2011)", en Cadernos Pagu, V.41, pp. 266-300

VARELA, Cecilia y GUTIÉRREZ, Jessica (2015) "Comercio sexual y efectos de las políticas anti-trata: un análisis a partir los procesos judiciales de la ley 26.364 (2008-2010)", en VII Congreso Iberoamericano de Estudios de Género, Universidad Nacional del Comahue

WIJERS, Marjan y LAP-CHEW, Lin (1999) Trafficking in women. Forced labour and slavery-like practices, GAATW, Bangkok

Revista Zona Franca- Centro de estudios interdisciplinario sobre las mujeres (CEIM)- Maestría poder y sociedad desde la perspectiva de género (MG), Rosario, Argentina. ISSN, 2545-6504 http://zonafranca.unr.edu.ar/index.php/ZonaFranca| Numero 24 (2016). 